Pirineos. Revista de Ecología de Montaña

Vol. 174

Jaca, Enero-Diciembre, 2019, e044

ISSN-1: 0373-2568

https://doi.org/10.3989/pirineos.2019.174004

\title{
DEMANDA TURÍSTICO-RECREATIVA Y EQUIPAMIENTOS DE USO PÚBLICO EN MONUMENTOS NATURALES PROTEGIDOS: LA “CUEVA DE LOS MURCIÉLAGOS” EN EL PARQUE NATURAL DE LAS SIERRAS SUBBÉTICAS
}

\section{Tourist-recreational demand and public use equipment in protected natural monuments: the "Cueva de los Murciélagos" in the natural park Sierras Subbéticas (Cordoba, Spain)}

\author{
Manuel Rivera Mateos ${ }^{1 *}$, Amalia Hidalgo Fernández², Ricardo Hernández Rojas² \\ ${ }^{1}$ Departamento de Geografía y Ciencias del Territorio. Universidad de Córdoba. 14071-Córdoba, España. \\ ${ }^{2}$ Departamento de Economía, Sociología y Política Agraria. Universidad de Córdoba.14071-Córdoba, España.
}

Identificador ORCID de los autores y e-mail:

Manuel Rivera Mateos: http://orcid.org/0000-0003-2780-380X. e-mail: manuel.rivera@uco.es Amalia Hidalgo Fernández: http://orcid.org/0000-0002-2764-6624. e-mail: es1hifea@uco.es Ricardo Hernández Rojas: http://orcid.org/0000-0002-3055-2151. e-mail: et2heror@uco.es *Autor de contacto.

\begin{abstract}
Recibido: 23-01-2019. Aceptado: 15-04-2019. Fecha de publicación on-line: 07/06/2019
Citation / Cómo citar este artículo: Rivera Mateos, M., Hidalgo Fernández, A., Hernández Rojas, R. (2019). Demanda turístico-recreativa y equipamientos de uso público en monumentos naturales protegidos: La "Cueva de los Murciélagos" en el Parque Natural de las Sierras Subbéticas. Pirineos, 174, e044. https://doi.org/10.3989/pirineos.2019.174004

RESUMEN: Para la gestión de los flujos turístico-recreativos en los espacios y monumentos naturales protegidos, su planificación medioambiental y el impulso del desarrollo local, la caracterización de los visitantes se revela como una necesidad básica. Cuando no cuentan con ésta, como es el caso del espacio de montaña media aquí estudiado, la planificación turística y medioambiental presenta notables deficiencias y los recursos patrimoniales y equipamientos de uso público suelen encontrarse infrautilizados y con problemas de funcionalidad y sostenibilidad, además de no responder adecuadamente a las expectativas de la demanda de visitantes. La aproximación que se realiza en este trabajo a la caracterización de ésta en este espacio natural protegido intenta orientar por ello sus políticas territoriales y sectoriales con incidencia en el turismo de naturaleza y su necesaria compatibilización con la conservación del patrimonio natural que le sirve de soporte y cualificación.
\end{abstract}

PALABRAS CLAVE: Espacios naturales protegidos; monumentos naturales; equipamientos de uso público; demanda turístico-recreativa; Sierras Subbéticas cordobesas; España. 


\begin{abstract}
For the management of tourist-recreational flows in protected natural areas, environmental planning and promotion of local development, the characterization of visitors is basic and when they do not have it, as the space studied, this planning suffers from deficiencies and its heritage resources and public use equipment are underutilized and do not always respond to demand expectations. The approach that is made in this paper to the characterization of this in this protected natural space tries to guide its territorial and sectoral policies with impact on nature tourism and its necessary compatibility with the conservation of the natural heritage that serves as support and qualification.
\end{abstract}

KEY WORDS: Protected Natural Areas; natural monuments; public use equipment; tourism and recreational demand; Sierras Subbéticas cordobesas; Spain.

\section{Introducción}

La demanda de turismo basada en el contacto y disfrute de la naturaleza ha crecido significativamente en España, si bien la oferta específica en algunos territorios españoles como Andalucía está aún lejos de conseguir los niveles de posicionamiento competitivo y de visibilidad en el mercado turístico de otras regiones españolas y europeas (Fernández \& Santos, 2010), como es el caso de las enclavadas en el área de la "España Verde" como Cantabria, Asturias, Navarra, el País Vasco y los Pirineos, con mayor tradición en la promoción y vertebración de este segmento turístico, una mayor articulación entre la oferta y la demanda e importantes ventajas competitivas en cuanto a nivel organizativo de sus equipamientos de uso público, infraestructuras y sistemas de calidad (Blanco, 2006; Rivera, 2010). De hecho, la demanda turística en Andalucía motivada principalmente por el turismo de naturaleza viene estando por debajo sensiblemente del $10 \%$ en los últimos años, tanto en los destinos de interior como del litoral (Turismo y Deporte Andaluz, 2016 y 2017).

Esta situación contrasta con el hecho de que Andalucía sea uno de los destinos turísticos españoles con mayor llegada de visitantes tanto nacionales como extranjeros y que ofrezca nada más y nada menos que 300 áreas protegidas integradas en la denominada Red de Espacios Naturales Protegidos de Andalucía (RENPA), que representa una extensión territorial de más 2,9 millones de hectáreas (un $32 \%$ de su superficie total), de las que 2,8 millones son terrestres, destacando la existencia de 2 parques nacionales (uno de ellos, Doñana, en la Lista Patrimonio de la Humanidad) y 24 parques naturales, en su mayoría localizados en áreas de montaña. Andalucía cuenta, en efecto, con un enorme patrimonio natural, una elevada cantidad de recursos naturales y una rica biodiversidad, siendo además la región española con mayor número de espacios protegidos en la Red Natura 2000 de la Unión Europea e incluso en otras tipologías de protección: 63 Zonas de Especial Protección para las Aves (ZEPA) y 189 Lugares de Interés Comunitario (LIC), de los cuales 149 están declarados Zonas Especiales de Conservación (ZEC); 9 Reservas de la Biosfera declaradas por la UNESCO, 25 Sitios Ramsar o Humedales de Importancia Internacional; 4 Zonas Especiales de Protección de Importancia para el Mediterráneo (ZEPIM) y 3 Geoparques Mundiales de la UNESCO. En este sentido, hay que destacar que uno de los conceptos mejor valorados por los visitantes en Andalucía es la calidad de los paisajes y parques naturales (Turismo y Deporte Andaluz, 2016 y 2017).

Basándose en la cantidad y calidad de estos recursos patrimoniales, así como en las tendencias en las inquietudes de los turistas rurales y de naturaleza, los expertos se muestran, en cualquier caso, optimistas con la evolución futura de este segmento de demanda en Andalucía en sus distintas facetas o espacios de negocio (Flores, 2008; Fernández \& Santos, 2010; Pulido \& Cárdenas, 2011). El modelo andaluz de protección y gestión de los parques naturales se orienta, al menos a nivel de discurso teórico, hacia la potenciación del desarrollo sostenible en estos territorios, más allá de la simple conservación de los ecosistemas, los paisajes y determinadas especies animales o vegetales (Consejería de Medio Ambiente, 2003). De esta manera, la cantidad y diversidad de estos espacios, que representan cerca del $40 \%$ de la superficie protegida bajo esta figura en toda España (Europarc-España, 2017), convierten a esta región en un territorio privilegiado para la práctica de todo tipo de actividades ligadas con la naturaleza, ya que éstas se realizan especialmente en los parques nacionales y naturales (Pulido, 2005).

El turismo rural y de naturaleza se puede convertir ciertamente en una herramienta fundamental para el desarrollo socioeconómico de las poblaciones situadas en el ámbito de influencia socioeconómica de estos espacios naturales protegidos (en adelante, ENP), pero para ello es necesaria una planificación y una gestión pública adecuadas desde el punto de vista medioambiental y turístico, lo que ciertamente no es fácil de aplicar, particularmente en territorios como el que aquí estudiamos, donde apenas existen estudios y evaluaciones previas sobre demanda y frecuentación turístico-recreativa, comportamiento de los flujos de visitantes, impactos ambientales, socioeconómicos y culturales previsibles y niveles de adecuación y funcionalidad de los equipamientos de uso público. Los estudios de caso se hacen, en este sentido, muy necesarios teniendo en cuenta la heterogeneidad de situaciones y casuísticas que pueden encontrarse en los espacios protegidos de la RENPA (Bel \& Arranz, 2011).

Así, por ejemplo, los Parques y Monumentos Naturales de Andalucía presentan una gran variedad interna tan- 
to por sus características territoriales intrínsecas como por los niveles de desarrollo socioeconómico de su ámbito de influencia (especialmente patente, en concreto, entre los parques naturales de zonas rurales y de montaña y los parques naturales de zonas litorales). Esto ha de subrayarse especialmente en Andalucía, ya que la declaración de estos espacios protegidos no ha respondido siempre a criterios consecuentes de racionalidad y a un diagnóstico territorial previo y bien estudiado, por lo que ha existido una cierta inercia a la uniformidad y la clonación de objetivos, estrategias e instrumentos de planificación y gestión del uso público. Y esto, a su vez, ha provocado que resulte difícil determinar su verdadera concepción como instrumentos de ecodesarrollo y revulsivo socioeconómico para áreas deprimidas (Mulero, 2001; Pulido, 2008). Por otro lado, no todos los parques y monumentos naturales se han declarado en Andalucía con la finalidad expresa de estimular estrategias de desarrollo sostenible, entre ellas la actividad turística, sino que hay territorios cuya declaración responde exclusivamente a la preservación ecológica y paisajística.

El nivel de actividad turística de los parques y monumentos naturales andaluces también es muy dispar (Fernández \& Santos, 2010), si bien existe un denominador común: los parques naturales en los que tradicionalmente ha existido un mayor grado de desarrollo turístico son, precisamente, los diez cuya extensión supera las 50.000 ha, más el Parque Natural de Cabo de Gata-Níjar en el litoral almeriense, no siendo el caso del Parque Natural de las Sierras Subbéticas cordobesas, que cuenta con poco más de 30.000 ha y un desarrollo del turismo rural y de naturaleza aun relativamente en ciernes. Pero, incluso en aquéllos, los indicadores como el grado de desarrollo turístico, la intensidad y nivel de especialización turística o la oferta de infraestructuras, equipamientos y actividades de uso público también son muy dispares (Mulero, 2001; Pulido, 2005; Fernández \& Santos, 2010).

Esta diversidad de situaciones y dinámicas en estos territorios también se hace evidente en las características, comportamientos y motivaciones de los visitantes como destinatarios de los equipamientos y programas de uso público, sin que sea posible establecer realmente un perfil de "visitante promedio" (Morales \& Guerra, 1996), por lo que es importante determinar los diversos tipos de usuarios de motivación turístico-recreativa y de esparcimiento en los ENP y, en consecuencia, establecer una segmentación de estos usuarios en función de sus características y necesidades. Y con todo esto se podrá orientar más adecuadamente el diseño, la gestión y la funcionalidad de los equipamientos de uso público, mejorar la información general sobre el significado y características del área protegida y conseguir que el visitante se sienta satisfecho y atraído por una experiencia agradable y enriquecedora, partícipe activo de la misma y con un sentimiento de pertenencia y acercamiento afectivo hacia el patrimonio (Blázquez, 2002).

Partiendo de estas consideraciones previas y de su contextualización, el objetivo de este artículo es aproximarnos a la caracterización de la demanda turístico-re- creativa de este parque natural y más concretamente del monumento natural más representativo del mismo, teniendo en cuenta tanto el perfil sociodemográfico como las motivaciones, expectativas y satisfacción de los visitantes que utilizan los equipamientos de uso público, así como la experiencia vivida de los turistas en el espacio natural protegido. Con ello se ha pretendido contribuir a ordenar el uso público para potenciar la función social del espacio protegido de forma compatible con la conservación de sus valores naturales y ofreciendo unos equipamientos de calidad adaptados a la demanda y la tipología de los visitantes. E igualmente se ha intentado aportar algunas orientaciones para establecer las medidas de gestión necesarias para la puesta en marcha de una posible propuesta de ordenación específica del enclave natural estudiado.

A este respecto, se ha seleccionado para el trabajo de campo de la encuesta el recurso patrimonial y equipamiento de uso público con registro oficial de visitantes que presenta mayor frecuentación en el Parque Natural en los últimos cinco años, la Cueva de los Murciélagos, declarada oficialmente como "Monumento Natural" por la Administración Regional en 2001 y, además, acondicionada y puesta en valor expresamente como equipamiento de uso público con un ecomuseo y centro de interpretación aledaño. Los resultados de la encuesta han sido complementados y comparados con los datos existentes de demanda de otros equipamientos de uso público del parque natural y con los obtenidos de una explotación específica de la encuesta oficial del Instituto Nacional de Estadística (INE) sobre ocupación de alojamientos de turismo rural. Con todo ello se ha pretendido obtener información útil para tomar decisiones con respecto a los equipamientos de uso público y su mejor adecuación para satisfacer a los usuarios y mejorar los servicios que éstos reciben, además de orientar los objetivos didáctico-informativos y de sensibilización y protección ambiental.

El estudio se divide en cuatro epígrafes. En el primero se tratan las cuestiones introductorias y los objetivos y planteamientos iniciales del trabajo, mientras que el segundo se centra en la contextualización territorial y la descripción de las características principales de este Monumento Natural. Posteriormente se continúa con un tercer y cuarto apartado dedicados, respectivamente, a la metodología y herramientas de investigación utilizadas y los resultados obtenidos junto con su discusión, para terminar con un apartado final de conclusiones.

\section{El ámbito territorial del estudio: el Parque Natural de las Sierras Subbéticas y el Monumento Natural de la Cueva de los Murciélagos}

Desde el punto de vista territorial el espacio natural protegido seleccionado ha sido el Parque Natural de las Sierras Subbéticas cordobesas, declarado como tal mediante el Decreto 232/1988, de 31 de mayo, de Presidencia de la Junta de Andalucía (BOJA, n 49, de 24-61988), antes incluso de la aprobación de la Ley 2/1989, 
de 18 de julio, del Inventario de Espacios Naturales Protegidos de Andalucía. La declaración de este parque natural persiguió en su día fundamentalmente la conservación del patrimonio natural de sus sierras compatibilizándolo con importantes y variados aprovechamientos tradicionales, entre los que se puede incluir el uso turístico ordenado. Sus valores excepcionales desde el punto de vista ecológico han hecho que con posterioridad se haya declarado este espacio como Zona de Especial Conservación para las Aves (ZEPA) en 2003, se haya incluido en la lista de Lugares de Importancia Comunitaria (LIC) de la Región Mediterránea en 2006 y se haya reconocido como Geoparque de España (2006) por el Comité Europeo de la Red Europea de Geoparques (Europeam Geoparks Networks), Geoparque Mundial de la UNESCO (2015) y Zona de Especial Conservación (ZEC) de la Red Ecológica Europea Natura 2000 en 2012.

Con una extensión de 32.056 ha, se encuentra situado estratégicamente en el centro geográfico de Andalucía y en una zona de transición entre las provincias de Córdoba, Málaga y Granada, a sólo unos $75 \mathrm{~km}$ de la capital cordobesa (Figura 1), conformándose como un espacio muy representativo desde el punto de vista naturalístico y paisajístico de la franja externa norte de las Cordilleras Béticas. Este espacio protegido, desde un punto de vista geográfico, se presenta a los ojos del visitante como un territorio de relieve accidentado, laberíntico y áspero; debido a sus alineaciones de montaña media mediterránea de origen alpino y sus paisajes típicamente kársticos, que alternan con margas y arcillas en los fondos conformando diversas formaciones de dolinas, poljés, lapiaces y abundantes cuevas.

Como principales instalaciones de atracción turística, el parque natural cuenta con un centro de visitantes (Santa Rita), un ecomuseo y centro de interpretación de la Cueva de los Murciélagos, declarada como Monumento Natural, y una red de miradores, senderos y áreas recreativas. Y son precisamente los georrecursos de la zona y diversos equipamientos ligados a los mismos los que se conforman como principales atractivos turístico-recreativos y didáctico-científicos por ser tan ilustrativos de la diversidad biológica, paisajística, arqueológica y cultural del espacio protegido.

La figura de Monumento Natural -que afecta a la Cueva de los Murciélagos- fue definida a nivel estatal por la Ley 4/1989, de 27 de marzo, de Conservación de los Espacios Naturales y de la Flora y Fauna Silvestres, posteriormente derogada por la Ley 42/2007 del Patrimonio Natural y la Biodiversidad, que también reconoció esta figura de protección en términos muy parecidos. Y también a nivel autonómico en Andalucía se regula esta mis-

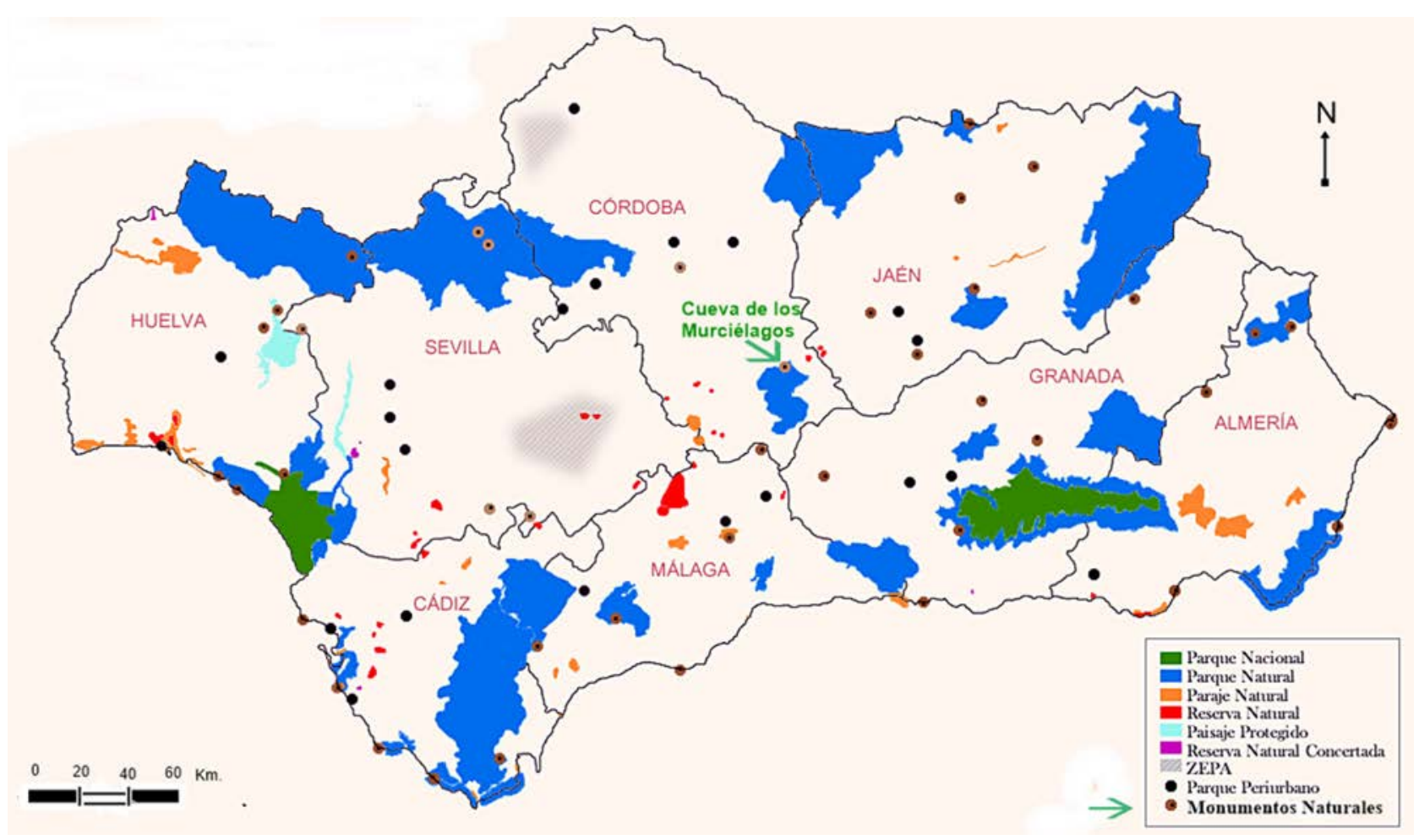

Figura 1: Mapa de localización de los Monumentos Naturales y la Cueva de los Murciélagos en el contexto territorial de la RENPA en Andalucía (2017). Fuente: Adaptación propia a partir de SIG REDIAM (Consejería de Medio Ambiente, Junta de Andalucía).

Figure 1: Map of the location of the Natural Monuments and the Cueva de los Murciélagos in the territorial context of the RENPA in Andalusia (2017). Source: Own adaptation based SIG REDIAM (Department of the Environment, Junta de Andalucia). 
ma figura por la Ley 2 /1989, de 18 de julio, por la que se aprueba el Inventario de los Espacios Naturales Protegidos y se establecen medidas adicionales para su protección, así como en el Decreto 225/1999, de 9 de noviembre, de Regulación y Desarrollo de la figura de Monumento Natural de Andalucía. Esta tipología de espacio protegido está pensada en la normativa regional y nacional de protección de la naturaleza para los espacios naturales y recursos patrimoniales de escasa extensión territorial pero de singularidad, rareza o belleza notorias y que merecen ser objeto de protección especial, habiéndose recuperado de las normativas de primeros de siglo XX para reconocerse después entre las seis categorías de protección de la Unión Internacional para la Conservación de la Naturaleza (UICN).

De esta forma, se pueden considerar Monumentos Naturales tanto las formaciones geológicas, los yacimientos paleontológicos o cualesquiera otros elementos de la Gea que reúnan un interés especial por la singularidad o importancia de sus valores científicos, culturales o paisajísticos, contribuyendo a garantizar una más completa representación de la biodiversidad y su subsistencia a medio y largo plazo, además de facilitar el conocimiento y disfrute del medio natural por todos los ciudadanos, ligándose en este caso muy oportunamente al turismo de naturaleza y el ecoturismo (Vacas, 2010 y Castillo, 2011). De acuerdo con los criterios establecidos en el artículo 4 del Decreto 225/1999 antes referido, en el que también se establecen las normas y directrices de ordenación y gestión de cada uno de los Monumentos Naturales de la RENPA de Andalucía (Figura 1), éstos pueden ser geológicos, bióticos, geográficos, ecoculturales y mixtos, además de afectar a enclaves singulares también diversos por sus valores ecológicos, paisajísticos, científicos y/o culturales (árboles centenarios, cascadas, cuevas, dunas, peñas, islas, etc.) y que pueden hallarse o no en el interior de otro espacio natural ya declarado.

Es el disfrute público el uso principal de estos espacios, donde debe destacar su valor didáctico (información y educación ambiental) y como recurso turístico para la atracción de visitantes (Europarc-España, 2005). Se incrementa así el interés económico de la conservación, promocionando elementos singulares susceptibles de ser rentabilizados en términos económicos y sociales, contribuyendo a encauzar y dirigir al emergente turismo interior y de naturaleza (Sancho \& Sousa, 2003) y el denominado "geoturismo", como es el caso de las cavidades subterráneas (Carcavilla et al., 2011). La Cueva de los Murciélagos responde a estas definiciones y principios en cuanto a su excepcionalidad y singularidad, reconocimiento social, potencial turístico y de uso público. Este tipo de monumento natural se pensó, no obstante, como figura de protección específica de aplicación a entornos muy singulares como es el caso que analizamos de una cueva kárstica y de gran valor arqueológico, pero lo cierto es que este objetivo primordial se ha visto sobrepasado por su función más reciente y cada vez más central en las últimas décadas como instrumento de fomento de las visitas al Parque Natural de las Sie- rras Subbéticas y para incrementar los recursos económicos para la población local a través del turismo de naturaleza.

No obstante, una serie de características propias de este espacio no son compartidas con la mayoría de los monumentos naturales declarados en Andalucía, como son su gran extensión, el grado de complejidad interna de este espacio y la alta concentración de valores patrimoniales tan diversos y procesos naturales. El acceso principal a la cueva tiene 1.000 metros de altura, una superficie de $324.591 \mathrm{~m}^{2}$ y un recorrido de unos dos kilómetros, siendo una de las cuevas más grandes de Córdoba y una de las formaciones más hermosas del Parque Natural de las Sierras Subbéticas. Este recurso patrimonial está situado en el término municipal de Zuheros, a tan sólo $2 \mathrm{~km}$ de la localidad y a unos 75 $\mathrm{km}$ de la ciudad de Córdoba, la capital de la provincia (Figura 2). Ofrece tanto espectaculares formaciones de estalactitas y estalagmitas como la posibilidad de conocer un yacimiento Neolítico con arte del Paleolítico Superior y pinturas rupestres animalísticas y humanas de gran interés, lo que ha propiciado su declaración como Bien de Interés Cultural, como es el caso de las representaciones de cabras, muy esquematizadas y nítidas, únicas de su estilo, y las figuras humanas pintadas durante el Neolítico (6.000-3.000 a.C.) y la Edad del Cobre o Calcolítico (3.000-2.000 a.C.). Todas estas características junto con su ubicación dentro de otra figura de protección superior como es un Parque Natural no han permitido durante mucho tiempo una gestión descentralizada de la cueva, al menos más allá de su cesión en fechas recientes por parte de la Consejería de Medio Ambiente al Ayuntamiento de Zuheros.

La visita a este monumento natural puede completarse, además, con el ecomuseo y centro de interpretación situado en sus inmediaciones, que cuenta con un servicio de recepción, información e interpretación relacionado con la gruta y situado a tan sólo $200 \mathrm{~m}$ de ésta. Y, asimismo, el municipio de Zuheros hace promoción conjunta de este recurso con otros atractivos de la villa como los miradores y entorno del Castillo roquero, de supuesto origen árabe, el torrente de agua del río Bailón, escoltado por enormes farallones calizos de la Sierra de Zuheros, el Museo Arqueológico y Etnográfico y la oferta gastronómica y de productos agroalimentarios de calidad como el queso tradicional de leche de cabra, típico de la zona (Figura 3). Las características excepcionales de la Cueva, sus atractivos variados y el acondicionamiento de su entorno como equipamiento de uso público y producto turístico relativamente bien ordenado e integrado en el conjunto de la oferta turística de la localidad de Zuheros, explica que sea hoy por hoy el recurso patrimonial más visitado del Parque Natural y con mucha diferencia respecto a otros equipamientos del territorio (Figura 4). Hay que tener en cuenta también que el turismo subterráneo, integrado como parte del activo natural y paisajístico de los ENP, cuenta con la ventaja de poder ofertarse en cualquier época del año con independencia relativa de las condiciones meteorológicas, 


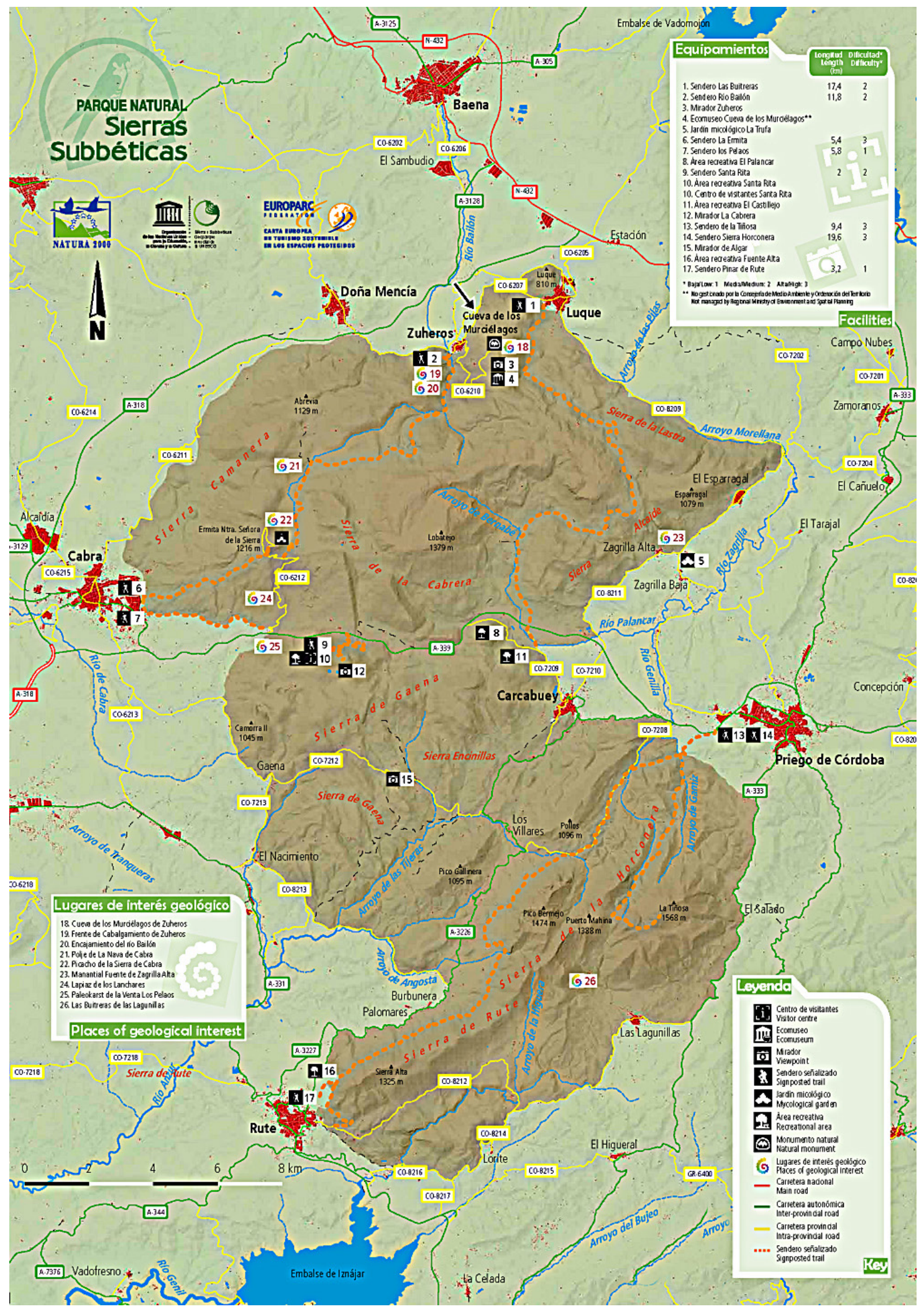

Figura 2: Mapa de equipamientos de uso público del Parque Natural con la localización de la Cueva de los Murciélagos (2017). Fuente: Adaptación propia a partir de SIG REDIAM (Consejería de Medio Ambiente, Junta de Andalucía).

Figure 2: Map of public use facilities of the Natural Park with the location of the Cueva de los Murciélagos (2017). Source: Own adaptation based SIG REDIAM (Department of the Environment, Junta de Andalucia). 


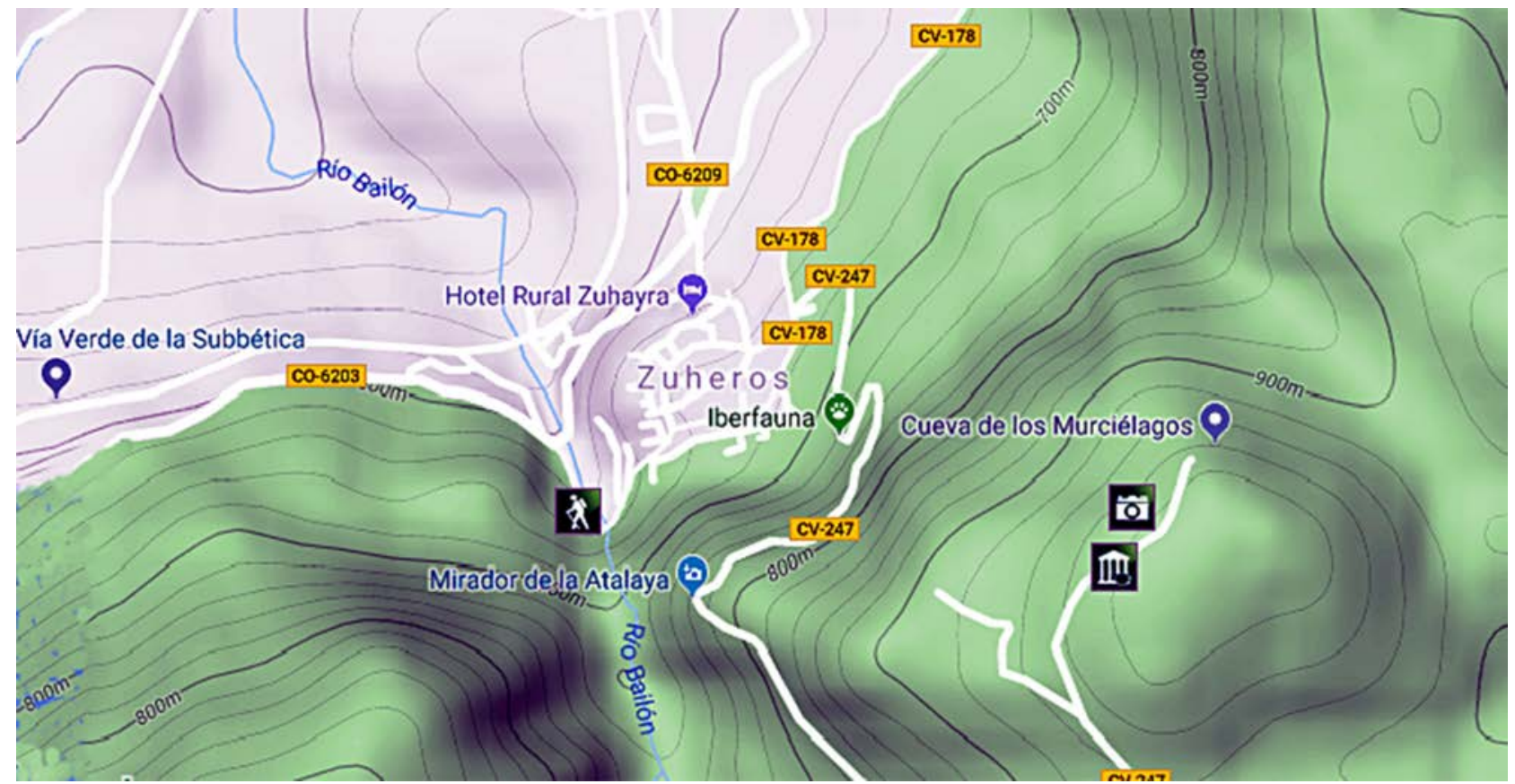

Figura 3: Entorno territorial y turístico cercano a la Cueva de los Murciélagos. Fuente: Base cartográfica y S.I.G. de la Red de Información Ambiental de Andalucía (REDIAM). Elaboración propia.

Figure 3: Territorial and tourist environment close to the Cueva de los Murciélagos. Source: Map base and S.I.G. of the Environmental Information Network of Andalusia (REDIAM). Own elaboration.

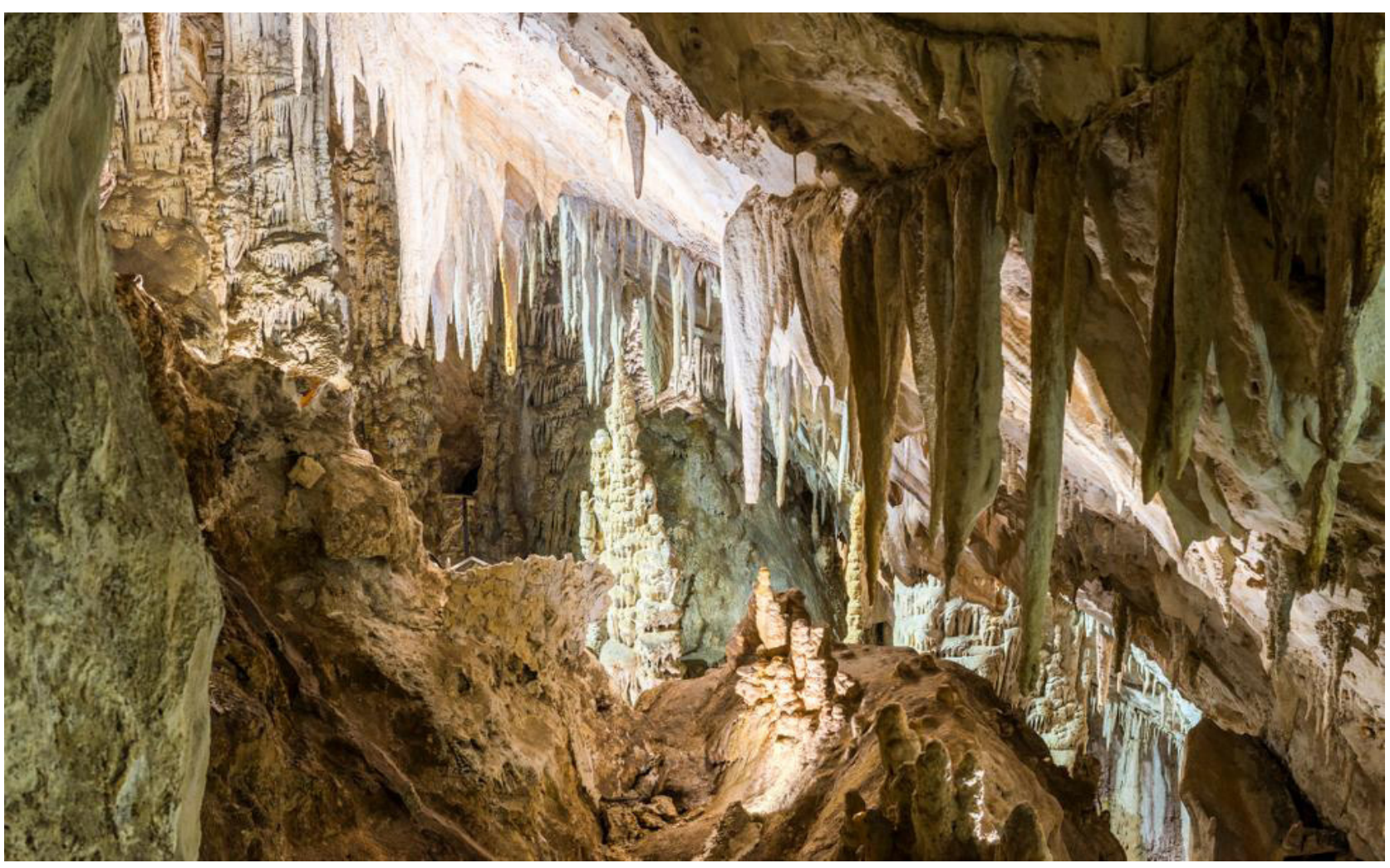

Figura 4: Imagen del interior de la Cueva de los Murciélagos. Foto: Manuel Rivera. Figure 4: Interior image of the "Cueva de los Murciélagos". Photo. Manuel Rivera 
por lo que las cuevas turísticas contribuyen, sin duda, a desestacionalizar la demanda de visitantes (Robledo \& Durán, 2011).

Nos encontramos, sin duda, ante un caso icónico de recurso patrimonial con fuerza de marca, autenticidad y diferenciación que actúa de catalizador para el desarrollo del turismo de naturaleza en el parque natural, fundamentando de esta forma la satisfacción de los turistas, como se ha podido comprobar en diversos estudios de casos relativos a otros recursos patrimoniales excepcionales (Blanquer, 2002). Asimismo, y en cierto modo, se considera incluso como un ejemplo de éxito relativo de colaboración interadministrativo en la gestión de equipamientos de uso público (Ayuntamiento de Zuheros, Consejería de Medio Ambiente y Mancomunidad de Municipios) y con cierta articulación formal y cultura colaborativa con el resto de la oferta turística, tanto pública como privada, del entorno de la localidad de Zuheros. Aunque prácticamente no se oferten en la zona "paquetes" de servicios y productos turísticos integrados, lo cierto es que se "paquetizan informalmente" o se promocionan conjuntamente distintos servicios de cara a mejorar la experiencia del cliente (cueva, ecomuseo, alojamiento, restauración, actividades, museos municipales, educación ambiental, Castillo, visitas a geo-recursos cercanos, etc.). Esta coordinación informal es posible gracias a lo limitado aún del sector turístico de la zona, que posibilita el conocimiento personal de los profesionales que actúan en él y el de otros agentes como el Ayuntamiento de Zuheros, que gestiona la Cueva de los Murciélagos, y la Mancomunidad de Municipios de las Subbéticas, cuya actividad principal es la promoción turística comarcal, dado que se concibió en los años ochenta del siglo pasado como un ente turístico supramunicipal.

Los estudios sobre monumentos naturales protegidos tanto en España como en Andalucía no son precisamente frecuentes, pese a su cada vez mayor tratamiento en la normativa medioambiental, y a diferencia de otras figuras de espacios naturales protegidos de mayor extensión y significación territorial como los parques naturales. Las referencias a esta tipología de espacios protegidos no deja de ser, de hecho, un tanto secundaria o tangencial en el marco de estudios más amplios sobre parques naturales, pero hemos podido recoger y consultar algunas obras de interés desde el punto de vista geográfico (Mulero, 2001), geomorfológico (Durán et al., 1998), de la gestión y ordenación del patrimonio protegido (Díaz-Martínez et al., 2008; Martínez, 2008; Barco et al., 2006; Mellado, 2006) y de la valoración económica del uso recreativo (González Trueba \& Serrano Cañadas, 2008; Robledo \& Durán, 2011). Y en cuanto a los estudios de especifica orientación turística y que incluyan análisis de la demanda y valoración de estos espacios singulares y de sus equipamientos de uso público, la bibliografía es aún más escasa, centrada sobre todo en algunas cavidades turísticas y con resultados muy limitados, salvo algunos estudios de caso aislados (Millán, 2001) con algunas aportaciones de interés para el análisis de las sinergias y discordancias entre la actividad turística y el uso público de los espacios naturales protegidos y sus recursos naturales y culturales.

\section{Metodología de la investigación}

Para realizar el estudio sobre el perfil de la demanda, se ha realizado previamente una búsqueda bibliográfica sobre estudios de caso y experiencias similares en parques naturales y otros espacios protegidos, que nos han permitido conocer las metodologías y herramientas de trabajo más habitualmente empleadas, sus puntos fuertes y débiles y algunas aplicaciones prácticas en este tipo de entornos territoriales. Esta bibliografía, recogida en el apartado final de este artículo, se ha completado con diversos trabajos de síntesis sobre planificación y gestión de espacios naturales protegidos y equipamientos de uso público desde la perspectiva de su adecuación a las necesidades de los usuarios potenciales y reales y la necesaria compatibilización de los objetivos de protección de la naturaleza con los de fomento del uso público y la demanda turístico-recreativa (Gómez-Limón, 2002). Finalmente, como principal método de investigación, se ha realizado un trabajo de campo consistente en la elaboración de una encuesta in situ a los visitantes de la Cueva de los Murciélagos como equipamiento de uso público y control de frecuentación de visitantes con mayor afluencia turístico-recreativa del parque natural.

La estructura y método de la encuesta se ha fundamentado en diferentes trabajos anteriores con resultados contrastados (Azqueta, 1996; Kozak, 2002; Ozdemir et al., 2012; Viñals et al., 2014). Se encuestó finalmente a 410 turistas que visitaron la Cueva durante los meses de enero a mayo de 2017. Las visitas al Monumento Natural son programadas y guiadas por un guía-monitor autorizado, por lo que las entrevistas personales se realizaron en la entrada a la cueva y en el ecomuseo que recoge una exposición de objetos prehistóricos e históricos de la misma y le sirve de antesala y recepción para los visitantes, ya que se encuentra a tan sólo 200 metros de su entrada principal. El muestreo se realizó de forma aleatoria estratificada con afijación proporcional por género y grupo de edad, para un nivel de error inferior al $5 \%$ y con carácter previo al trabajo de campo se ensayó la validez y adecuación del cuestionario con un total de 25 personas.

Las preguntas utilizadas en la encuesta han pretendido obtener algunos indicadores básicos para el estudio de la motivación y satisfacción de los visitantes de este espacio natural protegido. El índice de fiabilidad según el Alfa de Cronbach fue de 0,79 , ciertamente alto, lo que refuerza la validez del trabajo de investigación realizado (Nunnally $\&$ Bernstein, 1994). En la Tabla 1 se presenta la ficha técnica de la investigación realizada.

El cuestionario se estructuró en tres grupos de preguntas para obtener información sobre: 1) el perfil sociodemográfico y socioeconómico mayoritario del tu- 
Tabla 1. Ficha técnica de la encuesta. Fuente: Elaboración propia. Table 1. Survey technical sheet. Source: own elaboration.

\begin{tabular}{|c|l|}
\hline Población & Turistas de ambos sexos y mayores de 18 años que visitan la Cueva de los Murciélagos \\
\hline Muestra & 410 entrevistas personales válidas \\
\hline Error Muestral & $+/-5 \%$ \\
\hline Procedimiento & Aleatorio estratificado con afijación proporcional por género y edad \\
\hline Periodo de realización & Enero 2017-Mayo 2017 \\
\hline Control de Muestra & Coherencia y Estabilidad \\
\hline
\end{tabular}

rista; 2) las características del viaje de los visitantes de la cueva, y 3) sugerencias y comentarios enfocados hacía la mejora del turismo en la zona y sus equipamientos de uso público. El primer bloque está compuesto por las preguntas que ofrecen datos sobre las características socioeconómicas del turista que visita la cueva, el nivel de estudios, sexo, edad, estado civil y renta. El segundo bloque incluye las preguntas necesarias para conocer las actitudes de la población que visita la cueva, así como la frecuencia y duración de las visitas. Las preguntas van encaminadas a conocer las características y motivaciones del viaje tales como pernoctación, alimentación, compra de recuerdos y productos locales, recursos patrimoniales más valorados, etc. En este bloque se incluyen dos preguntas para conocer las opiniones de los turistas, una para identificar los motivos por los que visitan la cueva y otra para conocer los aspectos que potenciar en el entorno territorial más inmediato del Monumento Natural y para incrementar las visitas y mejorar el índice de satisfacción de los usuarios. Finalmente, el tercer bloque incluye una pregunta de sugerencias y comentarios donde se permitía al visitante expresar libremente lo que estimase conveniente para que pudiera servir de ayuda a las personas y entidades responsables que se encargan de la gestión del parque natural. Los datos recogidos fueron organizados, tabulados y analizados usando el programa SPSS 21.0, mientras que el tratamiento de los datos se ha realizado a través de la utilización de herramientas estadísticas univariantes y bivariantes, junto a correlaciones entre las variables.

\section{Resultados y discusión}

Los principales datos obtenidos correspondientes a las características socioeconómicas y el perfil sociodemográfico de los turistas que visitan la Cueva de los Murciélagos se recogen en la Tabla 2.

La proporción de encuestados por sexo refleja una relativa igualdad pero con una ligera representación de los hombres, con un $52 \%$ del total de visitantes, mientras que las mujeres representaron un $48 \%$. Los trabajadores por cuenta ajena, con un 49\%, son los profesionales más frecuentes en la muestra analizada y tan sólo un $18 \%$ del total de los encuestados declararon ser empresarios o autóno- mos, siendo éstos últimos mayoritarios en este segmento poblacional con un $12 \%$, seguidos de un $3 \%$ de profesionales independientes. Los estudiantes componen, por su parte, un grupo representativo con otro $18 \%$, mientras que las mujeres de mayor edad encuestadas se identifican como amas de casa en un 5\% de los casos, sin práctica presencia de hombres en este grupo sociodemográfico. Asimismo, el $6 \%$ de los entrevistados lo componen desempleados o personas sin empleo formal y el $4 \%$ son jubilados. La edad media del total de los visitantes de este Monumento Natural es de 40 años, siendo la edad mínima tenida en cuenta de 18 años y la máxima registrada de 70 años. Respecto al nivel socioeducativo, el $49 \%$ tienen estudios universitarios, el 30\% tienen titulación secundaria a nivel de Formación Profesional (FP) y Bachillerato y el 21\% cuentan tan sólo con estudios primarios.

Es de destacar el acentuado predomino de la demanda de visitantes de origen nacional (94\%), en paralelo a una muy reducida afluencia de los turistas extranjeros (sólo un $6 \%$ del total). Y, por último, con respecto al nivel de renta de los visitantes, el $37 \%$ de total de los encuestados posee una renta mensual disponible superior a $2.100 \mathrm{eu}-$ ros y un $31 \%$ entre 1.500 y 2.100 euros mensuales. La renta mensual disponible entre 900 y 1500 euros corresponde a un $27 \%$ del total de los encuestados, mientras que tan solo el 5\% tiene una renta de menos de 900 euros mensuales.

En cuanto a los resultados de las preguntas sobre las características del viaje (Tabla 3), podemos destacar, en primer lugar, cómo la mayoría de los turistas realizaron por primera vez esta visita al monumento natural (en un $82 \%$ de los casos). La mayoría de los turistas (70\%) no pernoctan en la zona debido a que la duración de la visita es inferior a 24 horas, mientras que el resto (un 20\%) ha elegido para su alojamiento un hotel en Córdoba capital, en alguna localidad comprendida en el parque natural o bien mayoritariamente en una casa rural $(69 \%)$ o en una caravana o camping (11\%). El gasto medio, por su parte, oscila entre 35-50 euros al día, existiendo mucha disparidad en los gastos según el municipio de procedencia del turista, así como la duración de la estancia y el tipo de alojamiento elegido.

Para la discusión y valoración de los resultados principales de esta encuesta hemos relacionado y asociado éstos últimos con la información obtenida expresamente para este trabajo de investigación de la explotación específica 
Tabla 2. Perfil sociodemográfico y económico de los visitantes de la Cueva de los Murciélagos. Fuente: Elaboración propia a partir de Encuesta a visitantes.

Table 2. Sociodemographic and economic profile of the visitors of the Cueva de los Murciélagos. Source: Own elaboration based Survey of visitors.

\begin{tabular}{|c|c|c|}
\hline Variable & Respuestas & Porcentajes \\
\hline \multirow{2}{*}{ Género } & Mujer & $48 \%$ \\
\hline & Hombre & $52 \%$ \\
\hline \multirow{4}{*}{ Edad } & Entre $18-30$ años & $18 \%$ \\
\hline & Entre 31- 45 años & $39 \%$ \\
\hline & Entre 46 - 60 años & $33 \%$ \\
\hline & Más de 61 años & $10 \%$ \\
\hline \multirow{3}{*}{ Nivel de estudios } & Elementales & $21 \%$ \\
\hline & Estudios medios & $30 \%$ \\
\hline & Estudios superiores & $49 \%$ \\
\hline \multirow{6}{*}{ Actividad laboral } & Empresario/Autónomo & $18 \%$ \\
\hline & Asalariado & $49 \%$ \\
\hline & Ama de casa & $5 \%$ \\
\hline & Estudiante & $18 \%$ \\
\hline & Jubilado & $4 \%$ \\
\hline & Desempleados/Sin empleo formal & $6 \%$ \\
\hline \multirow{8}{*}{ Lugar de procedencia } & Córdoba & $17 \%$ \\
\hline & Subbéticas & $11 \%$ \\
\hline & Aguilar & $1 \%$ \\
\hline & Zuheros & $2 \%$ \\
\hline & Resto provincia & $17 \%$ \\
\hline & Resto Andalucía & $25 \%$ \\
\hline & Resto España & $21 \%$ \\
\hline & Extranjeros & $6 \%$ \\
\hline \multirow{4}{*}{$\begin{array}{l}\text { Ingresos netos familiares } \\
\text { mensuales }(€)\end{array}$} & Menos de 900 euros & $5 \%$ \\
\hline & De $900 \mathrm{a}<1.500$ euros & $27 \%$ \\
\hline & De $1.500 \mathrm{a}<2.100$ euros & $31 \%$ \\
\hline & $>2.100$ euros & $37 \%$ \\
\hline
\end{tabular}

de una fuente secundaria de bastante interés como es la Encuesta de Ocupación de Alojamientos de Turismo Rural (EOTR) del Instituto Nacional de Estadística (INE), a través de la cual hemos podido conseguir datos desagregados a nivel territorial del Parque Natural de las Sierras Subbéticas cordobesas sobre número de viajeros de turismo rural, pernoctaciones, estacionalidad, estancia media y grado de ocupación. Con la explotación específica de los microdatos de esta encuesta para el año 2016 hemos podido acercarnos más detalladamente a las características y pautas de comportamiento de los turistas en este parque natural, utilizando como indicador principal el comportamiento de la ocupación de estos alojamientos, que son, en definitiva, los más vinculados de manera más precisa a la rentabilización del capital natural y cultural de este espacio protegido, al margen de otros establecimientos más convencionales o estandarizados como los hoteles, pensiones y hostales que están ubicados en espacios más propiamente urbanos de ciudades medias del entorno del parque natural como $\mathrm{Ca}$ bra o Priego de Córdoba.

En primer lugar, es de destacar que el predominio abrumador de los visitantes de origen nacional que hemos detectado en la encuesta de campo incide de manera decisiva en la débil ocupación anual, la limitada estancia media y la fuerte estacionalidad que se percibe en los datos de la EOTR del INE (Figuras 5 y 6), ya que estos parámetros de comportamiento son más propios del turismo nacional y de proximidad, aún cuando en la demanda de turistas genéricos rurales (no específicos de naturaleza) en el entorno territorial del parque natural tengan una mayor representación los visitantes extranjeros. Los niveles de ocupación (menos del 25\% anual en 
Tabla 3. Características y motivaciones del viaje asociado a la visita del recurso patrimonial. Fuente. Elaboración propia. Table 3. Characteristics of the trip associated with the visit of the patrimonial resource. Source. Own elaboration.

\begin{tabular}{|c|c|c|}
\hline Variable & Respuesta & Porcentaje \\
\hline \multirow{2}{*}{ Primera visita } & Sí & $82 \%$ \\
\hline & No & $18 \%$ \\
\hline \multirow{2}{*}{ N. ${ }^{\circ}$ de días } & Menos de 24 horas & $70 \%$ \\
\hline & Entre 2 y 3 días & $30 \%$ \\
\hline \multirow{3}{*}{ Tipo de alojamiento elegido } & Hotel & $20 \%$ \\
\hline & Casa rural & $69 \%$ \\
\hline & Autocaravana y Camping & $11 \%$ \\
\hline \multirow{3}{*}{ Gasto medio diario } & Menos de $35 €$ & $74 \%$ \\
\hline & Entre $36-50 €$ & $21 \%$ \\
\hline & Más de $51 €$ & $5 \%$ \\
\hline \multirow{4}{*}{ Motivación } & $\begin{array}{l}\text { Visitar y conocer la Cueva y pasear por } \\
\text { su interior }\end{array}$ & $40 \%$ \\
\hline & Conocer el territorio del Parque Natural & $19 \%$ \\
\hline & Turismo de naturaleza & $25 \%$ \\
\hline & Didáctica-científica & $16 \%$ \\
\hline \multirow{3}{*}{ Satisfacción con el destino } & Satisfecho & $78 \%$ \\
\hline & Indiferente o poco satisfecho & $22 \%$ \\
\hline & Insatisfecho & $0 \%$ \\
\hline ¿Repetiría la visita? & $\begin{array}{l}\text { Sí } \\
\text { No }\end{array}$ & $\begin{array}{r}\mathbf{9 8 \%} \\
2 \%\end{array}$ \\
\hline
\end{tabular}

los últimos años) son ciertamente bajos, en especial en comparación con los habituales en otras tipologías turísticas, ya que la demanda nacional presenta una fuerte concentración estacional en pocos días al año (fines de semana, Navidades, Semana Santa, "puentes festivos", etc.), frente a una demanda extranjera con hábitos de viaje turístico en el parque natural más repartidos a lo largo del año (Figura 5).

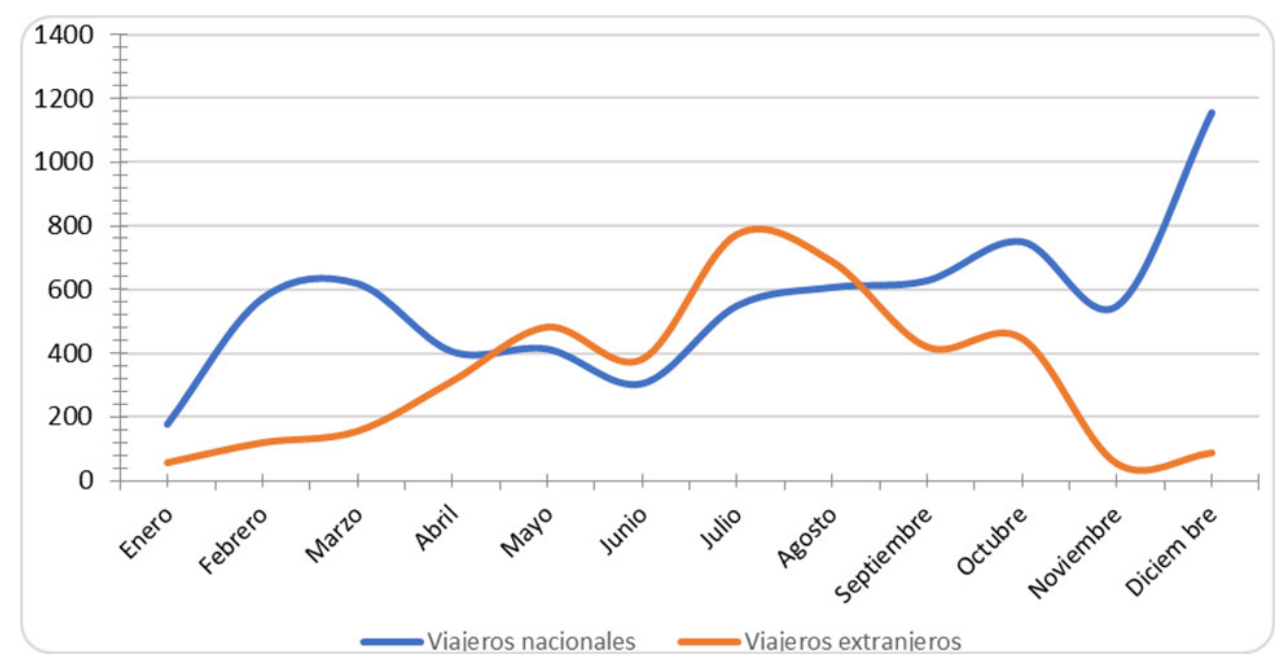

Figura 5: Número de viajeros en alojamientos rurales por meses (2016). Fuente: Explotación específica de la Encuesta Ocupación de Alojamientos Turísticos Rurales. INE 2016. Elaboración propia.

Figure 5: Number of travelers in rural accommodation for months (2016). Source: Specific exploitation of the Occupation Survey of Rural Tourist Lodgings. INE 2016. Own elaboration. 


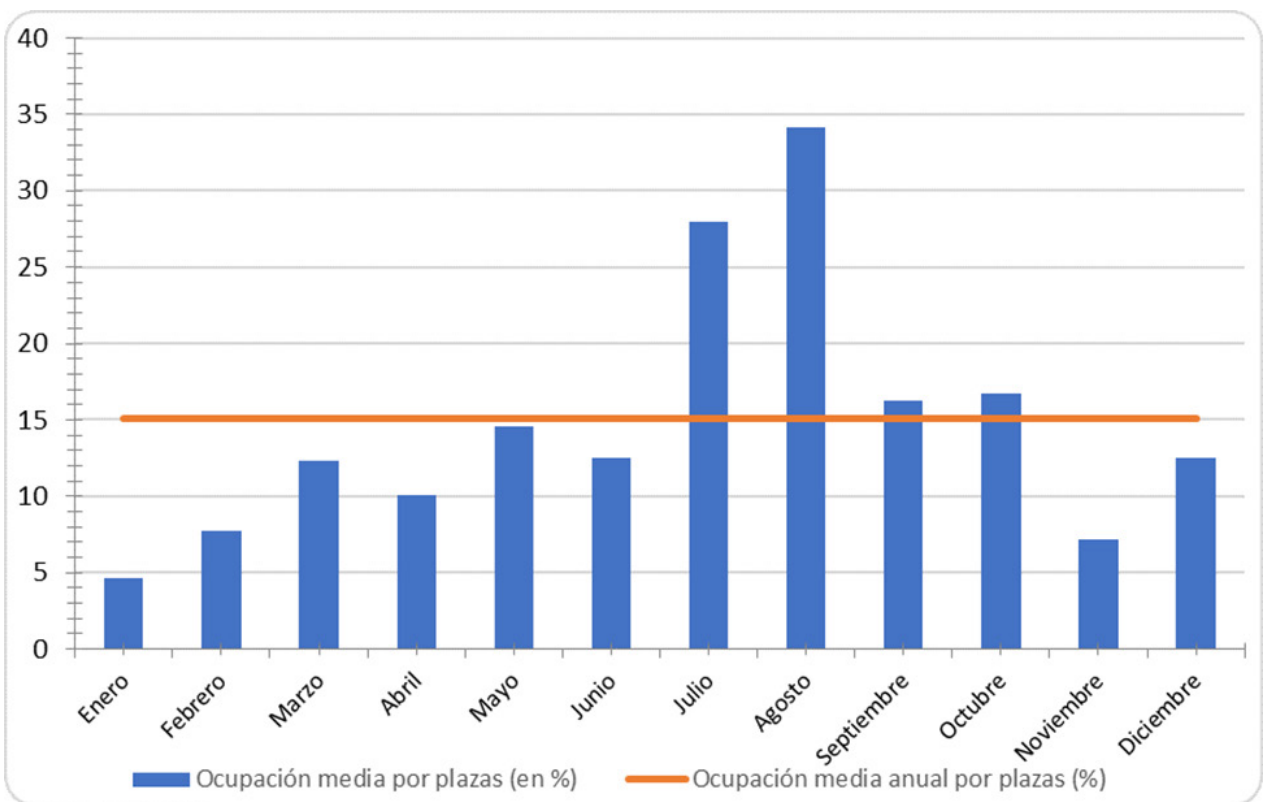

Figura 6: Ocupación media por plazas y meses en los alojamientos de turismo rural (2016). Fuente: Explotación específica de la Encuesta Ocupación de Alojamientos Turísticos Rurales. INE 2016. Elaboración propia.

Figure 6. Average occupancy by places and months in rural tourism accommodation (2016). Source: Specific exploitation of the Occupation Survey of Rural Tourist Lodgings. INE 2016. Own elaboration.

También es importante subrayar cómo el máximo de ocupación y afluencia de visitantes se produce en los meses de verano, pese a las rigurosas temperaturas estivales de esta zona serrana del interior de Andalucía. Esto puede explicarse por el hecho de que en ese período las estancias son más prolongadas (Figura 6), tanto de nacionales como de extranjeros sobre todo, sin limitarse a los fines de semana, como consecuencia de la coincidencia con el período vacacional por excelencia de los españoles y un cierto reflujo de turismo litoral extranjero procedente de Málaga y la Costa del Sol que al menos 1 o 2 días decide "escaparse" a las zonas de interior más cercanas y mejor comunicadas.

Con los cuestionarios codificados y resultados primarios de la encuesta se ha realizado, asimismo, un análisis bivariante obteniendo otras informaciones de interés para la discusión de aquéllos: 1) se ha podido comprobar la existencia de asociación entre las variables “¿Está satisfecho con el destino?” y “¿repetiría la visita?, con un estadístico $\chi^{2}=11,606(p$-value $=0.003)$, lo que nos indica que mejorando la satisfacción en general de la visita se incrementa la posibilidad de repetición; 2) existe igualmente asociación entre las variables ¿Cuál es su motivación para visitar la cueva? y ¿Satisfacción con la visita del destino?, con un estadístico $\chi^{2}=$ $10,878$ ( $\mathrm{p}$-value $=0.017)$, indicando cómo una mejor $\mathrm{y}$ cuidada visita al interior de la cueva, previamente orientada e interpretada por monitores o guías en el centro de interpretación y ecomuseo aledaño, facilitaría un mayor nivel de satisfacción del visitante $\mathrm{y}$, en consecuencia, una repetición mayor de las visitas y la fidelización de los turistas, lo que, de hecho, se ha podido reflejar en algunas observaciones realizadas por visitantes.

En principio, las condiciones bioclimáticas en la cueva pueden provocar situaciones negativas de carácter físico en los visitantes que la recorren, sobre todo debidas a la humedad ambiente, las temperaturas medias relativamente frías del interior de la cueva $\left(9^{\circ} \mathrm{C}\right)$ y las más frías en la entrada denominada "Cueva Chica", que llegan a alcanzar $\operatorname{los} 4^{\circ} \mathrm{C}$, a lo que hay que sumar los cerca de 700 escalones que hay que salvar en el recorrido completo de bajada y subida vertical, que pueden ocasionar puntualmente problemas de claustrofobia o agorafobia, cansancio físico e inconfortabilidad bioclimática (Vivas, 2009; Rivera, 2015). Pero lo cierto es que el grado de satisfacción de los visitantes que realizan el recorrido por el interior de la cueva es importante, de manera que los valores $\mathrm{y}$ atractivos patrimoniales del monumento natural acaban por compensar las dificultades e inconvenientes de tipo físico y motriz. De hecho, la mayoría de los turistas que visitan la cueva (un 98\%) están dispuestos a volver a la zona por el alto nivel de satisfacción alcanzado en la visita, especialmente paseando por el interior de la cueva pero también disfrutando de los atractivos paisajísticos, naturales y culturales de su entorno. Y es de destacar igualmente que los turistas extranjeros -que representan el $6 \%$ del total de los entrevistados- se sienten también recompensados, mostrando un buen nivel de satisfacción de la visita y su motivación principal de carácter naturalístico-cultural y/o didáctico-científico, según declaran mayoritariamente, pese a las molestias derivadas de recorrer largas distancias para llegar al destino, tener que usar 
como medio de transporte el avión para llegar a Andalucía y un coche de alquiler para desplazarse al parque natural y, asimismo, reservar el alojamiento en Córdoba capital o en el área de la Costa del Sol, desde donde se desplazan principalmente hacia las Sierras Subbéticas.

No obstante, también se han podido detectar en las encuestas algunas opiniones y recomendaciones de algunos visitantes más exigentes en relación con la falta de un servicio guiado más cualificado en lo que se refiere a la interpretación patrimonial de la cueva y una mayor calidad experiencial de la visita, como también sobre la mejor integración de este equipamiento con otras ofertas complementarias relacionadas con los geo-recursos del parque natural, que pasan en la práctica desapercibidos para muchos visitantes a los que sólo se les ofrece de manera aislada la Cueva de los Murciélagos. Y también es de reseñar la percepción que algunos visitantes manifiestan en la pregunta abierta final del cuestionario sobre cierto nivel de congestión y masificación de las visitas de grupos, lo que evidencia la necesidad de realizar en un futuro algún estudio pormenorizado sobre esta cuestión que pueda orientar algunas medidas de ordenación de los flujos de visitantes en la cueva.

La utilización complementaria en la discusión de los resultados de la encuesta de otras fuentes secundarias de interés como son las Memorias Anuales de la Junta Rectora del Parque Natural, -y en particular la explotación específica de las estadísticas de visitantes de los equipamientos de uso público principales- nos han permitido también poder realizar una comparativa de frecuentación entre la Cueva de los Murciélagos y el Centro de Recepción de Visitantes de este espacio protegido (Santa Rita). En este sentido, llama la atención que este último equipamiento de uso público con mejor posición de centralidad geográfica en el parque natural y muy próximo a georrecursos claves como el lapiaz de Los Lanchares, el Picacho de la Virgen de la Sierra o el poljé de la Nava (Figura 2), no haya supuesto un factor importante de atracción turística. Y esto también pese a su gestión medioambiental directa por la Administración Autonómica, que lo considera como equipamiento central y principal del parque natural y aun cuando cuenta con instalaciones de acogida e información general del espacio protegido, aseos, señalización, aparcamiento y un sendero botánico aledaño, además de estar bien conectado por carretera. Y es que se trata de un equipamiento meramente básico y artificial, que en la práctica presenta escaso atractivo por sí mismo y cuenta con una oferta de uso público mal articulada e integrada funcionalmente con los recursos naturales y patrimoniales más representativos de la integridad ecológica y paisajística del parque natural y con otros equipamientos de uso público del mismo. En consecuencia, despierta poco interés para su visita, para la que no se cuenta tan siquiera con servicio de conducción, información personalizada e interpretación a través de guías o monitores especializados. De esta manera, muchos turistas suelen obviar este centro en sus visitas al parque natural, como se aprecia en la gran diferencia entre el número de sus visitantes y los de la Cueva de los Murciélagos (Figura 7) y en el hecho de que su valoración como equipamiento y recurso turístico sea muy inferior a ésta última, cuya autenticidad y excepcionalidad como monumento natural protegido es la principal motivación y satisfacción de la demanda, además de otros factores de atracción como el impacto sensorial y emocional que genera en los visitantes y su identificación como auténtico icono interpretativo de los recursos patrimoniales del parque natural (Rivera, 2015).

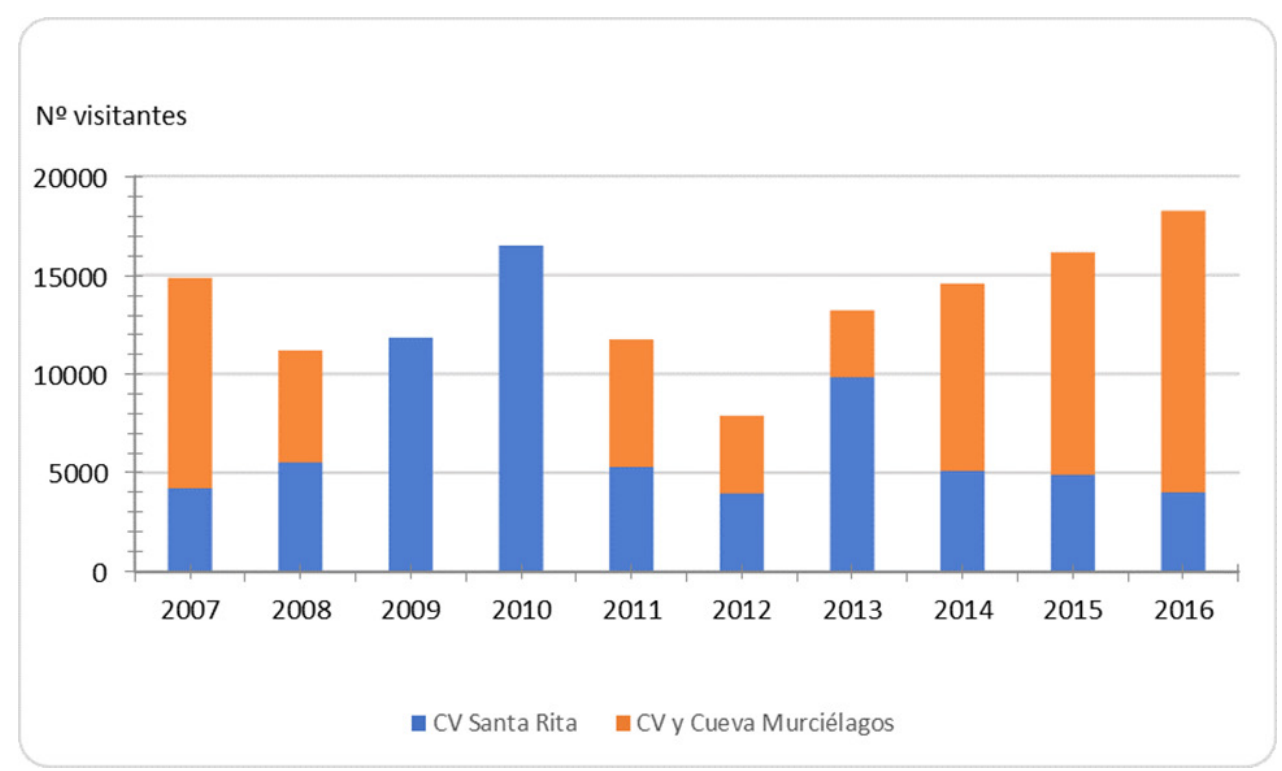

Figura 7: Evolución del número de visitantes en los centros de recepción de visitantes de Santa Rita y Cueva de los Murciélagos (2007-2016). Fuente: Memorias Anuales del Parque Natural (Junta Rectora). Elaboración propia

Figure 7: Evolution of the number of visitors at the visitor reception centers of Santa Rita and Cueva de los Murciélagos (2007-2016). Source: Annual Reports of the Natural Park. Own elaboration 


\section{Conclusiones y recomendaciones}

Los monumentos naturales, como el caso estudiado de la Cueva de los Murciélagos, suelen contar con los rasgos más auténticos y singulares de cada territorio (Dearden et al., 2005; Boned, 2006), de manera que presentan valores patrimoniales que hacen generalmente satisfactoria su visita, convirtiéndose en auténticos atractivos turísticos con una importante fuerza de marca e incluso en iconos catalizadores del turismo rural y de naturaleza en los espacios naturales protegidos. Los resultados obtenidos nos han permitido conocer un caso de relativo éxito que parece satisfacer realmente las expectativas de los turistas, aun cuando éstos manifiesten que todavía es mejorable la experiencia turística en el interior de la Cueva, así como la promoción y la gestión de la misma. En este sentido, destaca la apreciación de la necesidad de una mayor complementariedad y asociación de la visita al monumento natural con la oferta turística de la zona, así como con diversas actividades de ocio guiadas tanto para grupos como para familias, que son precisamente los dos colectivos mayoritarios de visitantes.

Del análisis realizado sobre la demanda turística en el equipamiento de uso público seleccionado, podemos afirmar que, pese a las valoraciones positivas sobre la experiencia turística de los visitantes, es posible mejorar su nivel de satisfacción y confort psicológico si se potencian más las condiciones de acceso físico e intelectual a los recursos patrimoniales y los equipamientos de uso público, así como su conocimiento emocional y de manera atractiva. Y es que aunque el turismo de naturaleza ha experimentado un cierto crecimiento en la zona, las cifras de turistas en este parque natural muestran aún una considerable distancia con respecto a los niveles de consolidación y maduración registrados en parques naturales de otras muchas zonas de Andalucía y España.

El resultado de este proceso se traduce en una estimación todavía muy modesta de los turistas de naturaleza en este espacio protegido, pese al aumento experimentado en los últimos años una vez superado el período de crisis económica de finales de la primera década de este siglo. Además, se trata de turistas de proximidad en su mayor parte, procedentes de la capital cordobesa y en segundo término de Málaga, que generan un escaso gasto diario, y que muchas veces ni tan siquiera realizan prácticas de turismo de naturaleza sino que acuden al Parque Natural por su proximidad a ciudades medias de importante oferta patrimonial y turística como Cabra o Priego de Córdoba, que representan un papel más importante desde el punto de vista productivo turístico en relación a su entorno. Todo esto se acusa en el ya señalado problema de la débil ocupación anual de los alojamientos de turismo rural; debilidad ésta que se deriva sobre todo de la excesiva dependencia de la demanda nacional y la marcada estacionalidad de la misma en pocos días del año. En consecuencia, sería necesario enfatizar en la mejora y recualificación de la oferta de uso público como principal factor que podría redundar de manera importante en la afluencia de usuarios, sobre todo extranjeros, ya que éstos parecen distribuir mejor a lo largo del año sus desplazamientos para la práctica del turismo rural y de naturaleza y además integran una demanda mejor estructurada por segmentos temáticos y de mayor estancia media.

No basta, en este sentido, con generar equipamientos con servicios básicos de utilización general para los visitantes como los de información e interpretación pasiva del patrimonio tangible, sino que hay que introducir también variables propias del denominado "turismo experiencial" como la componente sensitivo-emocional que debe comportar la visita como atributo del espacio protegido, lo cual lleva a generar sentimientos positivos de satisfacción y actitudes de aprecio sobre el disfrute, protección y conservación del lugar (Rivera, 2015). En definitiva, se hace patente la necesidad de intensificar los canales de comercialización y centrar el producto en la oferta de actividades y vivencias diferenciadas, más vinculadas al capital natural singular del territorio.

Por otra parte, se deduce de los resultados obtenidos la importante ayuda que pueden prestar los monitores o guías-intérpretes de naturaleza a la hora de facilitar la conexión del medio natural con los visitantes, hasta incluso para resolver situaciones un tanto adversas de confortabilidad como los que se pueden dar en la Cueva de los Murciélagos. Por añadidura, como se ha podido comprobar en otros estudios (Tian-Cole \& Crompton, 2003), además de la satisfacción global de los turistas debe cuidarse la calidad de la experiencia buscando beneficios para los mismos como la calidad de los equipamientos y servicios y la atención al público por parte del personal (amabilidad, preparación, profesionalidad, etc.), que hemos comprobado cómo son mejor gestionados en la Cueva de los Murciélagos que en el Centro de Visitantes de Santa Rita, donde ni tan siquiera existen guías-intérpretes ni monitores e incluso este servicio ha ido en regresión en los últimos años.

Otros aspectos que mejorar en la Cueva de los Murciélagos, según las manifestaciones de los encuestados, son el transporte público, la información a los visitantes, las rutas señalizadas, la oferta complementaria de ocio para familias con niños y la mejora de la accesibilidad global, que podría atenderse, por ejemplo, con APPS adaptadas para usuarios con problemas auditivos o visuales, textos explicativos adaptados y audioguías. Estas mejoras, junto con una mayor y mejor promoción del monumento natural, podrían facilitar un mayor número de pernoctaciones en el entorno del parque natural y una mayor estancia media, superando la situación actual donde el espacio protegido es objeto sobre todo de visitas de excursionistas que pernoctan en ciudades como Córdoba y Málaga y que, por tanto, no permanecen ni tan siquiera un día en este destino.

Y, por último, hemos de destacar la necesidad de que el monumento natural de la Cueva de los Murciélagos se dote de un Plan de Ordenación y Gestión integral y específico y de un estudio de capacidad de carga turístico-recreativa, teniendo en cuenta la fragilidad medioambiental de este recurso patrimonial y la importante afluencia de visitantes de diversos perfiles que registra (espeleólogos, 
arqueológicos y científicos, familias y grupos de amigos, escolares, tercera edad, turistas generalistas y especializados, etc.). En este sentido, resulta necesario atender y considerar la percepción de los usuarios sobre la posible saturación y congestión de las visitas (Leco et al., 2013), o sea, la capacidad de carga perceptual como una variable importante a la que dedicar atención para una adecuada gestión de esta área de uso público. Actualmente, ni tan siquiera se han establecido los límites por encima de los cuales se garantiza la sostenibilidad ambiental de la cueva, mientras que su gestión, cada vez más centrada en su orientación turístico-recreativa, apenas está sometida a parámetros sustantivos de sostenibilidad. En este sentido, hemos apreciado la insuficiencia e inconveniencia de las actuaciones aisladas, inconexas y meramente reactivas que se han venido aplicando hasta la fecha, como la instalación de iluminación con lámparas Led, el cambio de cancela enrejada de acceso a la cueva para facilitar el paso de la población de murciélagos o la limitación de aforo para grupos de visitantes de 40 a 30 personas por turno cuando se detectó tardíamente la afectación a las condiciones microclimáticas de la cueva. Algunas medidas como la disposición de un sistema de sensorización y control medioambiental para la vigilancia de los efectos del paso de visitantes en la cavidad, las variaciones en los índices de humedad, temperatura y $\mathrm{CO}_{2}$, e incluso la detección de usuarios que se encuentren fuera del recorrido oficial y en zonas de acceso restringido o prohibido.

\section{Referencias}

Azqueta, D., 1996. Métodos para la determinación de la demanda de servicios recreativos de los espacios naturales. En: Azqueta, D. y Pérez, L. (Eds.). Gestión de espacios naturales. La demanda de servicios recreativos. Mcgraw-Hill, Madrid, pp. 51-74.

Blanco, R., 2006. El turismo de naturaleza en España y su Plan de Impulso. Estudios Turísticos, 169-170: 7-38.

Blanquer, D., 2002. Ordenación y gestión del territorio turístico. Tirant lo Blanch, Valencia.

Barco, P.M., Alonso-Zarza, A.M., Sánchez-Moral, S., Flores, E.M., Cueva, S., Gil-Peña, I. \& Martín-Pérez, A., 2006. Los estudios científicos como herramienta para la conservación y gestión del Monumento Natural Cueva de Castañar (Extremadura). Trabajos de Geología, 26: 175-185.

Bel, C. \& Arranz, A., 2011. El turismo y el desarrollo rural en los parques naturales. El caso del Parque Natural Sierra de Grazalema. Spanish Journal of Rural Development, 2: 1-22.

Blázquez, M., 2002. Uso público del patrimonio natural. En: Blázquez, M. (Coord.). Geografía y territorio. El papel del geógrafo en la escala local. Universitat de les Illes Balears, Palma de Mallorca, pp. 202-210.

Boned, R., 2006. Manual de turismo sostenible. Araucaria XXI: fundamentos y buenas prácticas. Agencia Española de Cooperación Internacional, Madrid.

Castillo, R.C., 2011. La conceptualización de los segmentos turísticos en Andalucía: una breve aproximación. Turydes, 4 (10). Disponible en: http://www.eumed.net/rev/turydes/10/ ccr.pdf.

Carcavilla, L., Belmonte, A., Durán, J.J. \& Hilario, A., 2011. Geoturismo: concepto y perspectivas en España. Enseñanza de las Ciencias de la Tierra, 19 (1): 81-94.
Consejería de Medio Ambiente, 2003. Gestión de Uso Público en la RENPA. Estrategia de Acción. Junta de Andalucía, Sevilla.

Dearden, J., Bennett, M. \& Johnston, J., 2005. Trends in global protected area governance, 1992-2002. Environmental Management, 36(1): 89-100. doi: 10.1007/s00267-004-0131-9

Díaz-Martínez, E., Guillén, M.F., Mata, J.M., Muñoz, P., Nieto, L., Pérez-Lorente, F. \& Santisteban, C. D., 2008. Nueva legislación española de protección de la Naturaleza y desarrollo rural: implicaciones para la conservación y gestión del patrimonio geológico y la geodiversidad. Geo-Temas, 10: 1311-1314.

Durán, J.J., Brusi, I, Belmonte, D., Pallo, I, Buxó, L., López, J., Palacio, J. \& Vallejo, M., 1998. Geología ecológica, geodiversidad, geoconservación y Patrimonio Geológico de la Declaración de Girona. En: IV Reunión Nacional de la Comisión de Patrimonio Geológico: Miraflores de la Sierra. Comunicaciones. Sociedad Geológica de España, Madrid, vol. 1, pp. 69-72.

Europarc-España, 2005. Manual sobre conceptos de uso público en los Espacios Naturales Protegidos. Fundación Fernando González Bernáldez, Madrid.

Europarc-España, 2017. Anuario 2016 del estado de las áreas protegidas de España. Fundación Fernando González Bernáldez, Madrid.

Fernández, A. \& Santos, E., 2010. Turismo y parques naturales en Andalucía tras veinte años desde su declaración. Análisis estadístico, tipologías y problemática de situación actual. Anales de Geografia de la Universidad Complutense, 30 (1): 29-54.

Flores, D., 2008. Segmentación del turismo en parques naturales como estrategia de competitividad. Un análisis comparado en Andalucía. Papers de Turisme, 43-44: 69-82.

Gómez-Limón, J., 2002. La demanda turística en espacios naturales. En: Viñals, M.J. (Coord.). Turismo en espacios naturales y Rurales II. Universidad Politécnica de Valencia, Valencia, pp. 117-137.

González Trueba, J.J. \& Serrano Cañadas, E., 2008. La valoración del patrimonio geomorfológico en espacios naturales protegidos: su aplicación al parque nacional de los Picos de Europa. Boletín de la Asociación de Geógrafos Españoles, 47: 175-194.

Kozak, M., 2002. Comparative analysis of tourist motivations by nationality and destinations. Tourism Management, 23 (3): 221-232. https://doi.org/10.1016/S0261-5177(01)00090-5

Leco, F., Pérez, A. \& Mateos, B., 2013. Uso público y capacidad de carga perceptual en espacios naturales protegidos. Papeles de Geografía, 57-58: 127-143.

Martínez, O.R., 2008. Patrimonio geológico. Identificación, valoración y gestión de sitios de interés geológico. Geograficando, 4 (4): 233-250.

Mellado, S., 2006. Ordenación del uso público en el Monumento Natural Cerro del Hierro: medidas para la gestión. Universidad de Huelva, Trabajo Fin de Máster inédito, Huelva.

Millán, M., 2001. Interrelación entre la actividad turística y los espacios naturales protegidos. Cuadernos de Turismo, 7: 93-110.

Morales, J. \& Guerra, F., 1996. Uso público y recepción en espacios naturales protegidos. La atención a los visitantes reales y potenciales. En: Seminario Permanente de Educación Ambiental en Espacios Naturales Protegidos. MOPT, Madrid, pp. 1-25.

Mulero, A., 2001. Los espacios naturales protegidos en Andalucía: evolución, caracterización geográfica y singularidades. Ería, 54-55: 141-157.

Nunnally, J. \& Bernstein, L., 1994. Psychometric Theory. McGraw-Hill, Nueva York. 
Ozdemir, B., Cizel, B. \& Cizel, R.B., 2012. Satisfaction with all inclusive tourism resorts: the effects of satisfaction with destination and destination royalty. International Journal of Hospitality \& Tourism Administration, 20 (13):109-130. https://doi.org/10.1080/15256480.2012.669313

Pulido, J.I., 2005. Criterios para una política turística sostenible en los parques naturales de Andalucía. Consejería de Turismo, Comercio y Deporte, Junta de Andalucía, Sevilla.

Pulido, J.I., 2008. Gestión turística activa y desarrollo económico en los parques naturales andaluces. Una propuesta de revisión desde el análisis del posicionamiento de sus actuales gestores. Revista de Estudios Regionales, 81: 171-203.

Pulido, J.I. \& Cárdenas, P.J., 2011. El Turismo rural y de naturaleza en Andalucía. Diagnóstico y perspectiva estratégica. En: Jurado, J.M. (Coord.) Recursos, potencialidades y modelos turísticos en el Baixo Alentejo, Algarve y provincia de Huelva. Universidad de Huelva, Huelva, pp. 63-88.

Rivera, M., 2010. Turismo activo en la naturaleza y espacios de ocio en Andalucía. Consejería de Turismo, Comercio y Deporte, Junta de Andalucía, Sevilla.

Rivera, M., 2015. Turismo experiencial y gestión estratégica de recursos patrimoniales: un estudio de percepción de productos turísticos en las Sierras Subbéticas cordobesas. Scripta Nova. Revista de Geografía y Ciencias Sociales, 511: 1-34.

Robledo, P.A. \& Durán, J.J., 2011. Geoturismo y cavidades: perspectivas en las Islas Baleares. En: Anais do $31^{\circ}$ Congresso
Brasileiro de Espeleologia. Punta Grossa: Sociedad Brasileña de Espeleología, Río de Janeiro, pp. 189-200.

Sancho, F. \& Sousa, A., 2003. Bases y criterios para la declaración de monumentos naturales de Andalucía. Junta de Andalucía, RENPA, Sevilla.

Tian-Cole, S. \& Crompton, J., 2003. A conceptualization of the relationships between service quality and visitor satisfaction, and their links to destination selection. Leisure Studies, 22 (1): 65-80. https://doi.org/10.1080/02614360306572

Turismo y Deporte Andaluz, S.A., 2016: Turismo de Naturaleza. Año 2016. Consejería de Turismo y Deporte, Junta de Andalucía, Sevilla.

Turismo y Deporte Andaluz, S.A., 2017: Turismo español y extranjero en Andalucía. Demanda Turística en Andalucía. Consejería de Turismo y Deporte, Junta de Anadalucía, Sevilla.

Vacas, T., 2010. Patrimonio natural: uso público/turístico en los espacios naturales protegidos españoles. Estudios Turisticos, 186: 69-91.

Viñals, M.J., Morant, M. \& Teruel, L., 2014. Confort psicológico y experiencia turística. Casos de estudio de espacios naturales protegidos de la Comunidad Valenciana (España). Boletín de Asociación de Geógrafos Españoles, 85: 293 316. http://dx.doi.org/10.21138/bage. 1754

Vivas, G.F., 2009. El espacio público como parte del sistema de lugares en tres casos de estudios. Fermentum, 54: 11-34. 